\title{
SINDROME TRAUMÁTICA CENTRAL AGUDA DA MEDULA CERVICAL
}

\author{
Augusto Gentil Baptista *
}

Um quadro clínico curioso, resultante de traumatismo raquimedular, vem sendo insistemente estudado por Schneider e seu grupo 5, 6, 7, 3, 9, 10 com o titulo de "syndrome of acute central cervical spinal cord injury", título aqui traduzido por sindrome traumática central aguda da medula cervical. Embora Schneider e Schemm ${ }^{10}$ digam ter sido ela descrita pela primeira vez em 1954, Gros e col. ${ }^{1}$ referem-se a Dide, Claude e Lhermitte, em 1917, como os primeiros a relatá-la, enquanto Rand e Crandall ${ }^{4}$ atribuem a Bailey, em 1900, e a Thorburn, dez anos antes, a primazia do seu registro.

O presente relato, de dois casos, visa chamar a atenção para uma sindrome que parece ser pouco conhecida, tanto em nosso meio, como alhures. Embora de cbservação infreqüente, não é de todo rara, e é de valor o seu conhecimento quando se contempla a necessidade de descompressão cirúrgica nos traumatismos raquimedulares cervicais.

Caso 1 - J.J.S., masculino, pardo, 65 anos, agricultor, registro $n^{\circ} 115025$ do Hospital Prof. Edgard Santos, examinado em 20-3-1963. Relatou o paciente que 8 meses antes, isto é, em julho de 1962, viajava na cabine de uma caminhoneta quando esta, ao fazer uma curva e tendo-se a carga deslocado de um lado para o outro, capotou, "virando as rodas para o ar"; não houve choque violento do veículo contra qualquer obstáculo. O paciente perdeu os sentidos por alguns instantes e com èles os pormenores sôbre a maneira dos traumatismos que sofreu. Supôs não ter batido a cabeça no pára-brisas, pois não se quebraram os seus óculos. Não sofreu escoriações, nem fraturas de monta. Logo ao recobrar os sentidos tinha completo domínio das funçōes mentais e pôde andar perfeitamente bem. Alguns instantes depois, num "jeep" que o transportava, segurando a alça própria do painel, comecou a sentir formigamento em ambas as mãos, seguido de dor nas mesmas e ao longo dos membros superiores; manteve, no entanto, fôrça suficiente para continuar a segurar-se à alça. Dor e formigamento se foram intensificando, requerendo uso de analgésicos. Internado em hospital, gradativamente instalou-se paralisia dos membros superiores, a qual já era completa passados dois ou três dias. Tal paralisia demorou cêrca de 2 meses, principiando então a regredir; dor e formigamento cederam, embora incompletamente, persistindo aquela no membro superior direito. Quando visto no Hospital Edgard Santos queixava-se, ainda, de certa dificuldade na movimentação dos ombros e no fechamento completo das mãos. Em nenhum momento houve perturbação da motilidade nem da sensibilidade dos membros pélvicos, nem distúrbios de esfincteres. Também nenhuma perda de sensibilidade nos membros superiores, ao que disse o paciente, embora o tocar-lhe ou picar-lhe produzisse sensação associada de "choque elétrico". Havia queixa de, ao fletir a cabeça, "choque elétrico" ao longo da espinha até as pernas.

Docente-livre de Clinica Neurológica da Faculdade de Medicina da Universidade da Bahia; Chefe do Serviço de Eletrencefalografia do Hospital Prof. Edgard Santos. 
O exame físico mostrava paciente em bom estado geral, com restrição dos movimentos das articulações escápulo-umerais, metacarpofalangianas e interfalangianas, tanto à direita como à esquerda, atribuida a desuso. As anormalidades neurológicas restringiam-se ao sinal de Lhermitte e alterações nos reflexos osteotendinosos dos membros torácicos: à direita, bicipital "invertido" e, do mesmo modo, estilo-radial com resposta de flexão dos dedos mais ativa que a de flexão do antebraço, sendo os homónimos esquerdos normais; os outros, aumentados de intensidade, sobretudo á direita, com sinal de Hoffmann dêsse lado.

Espondilartrose moderadamente severa revelaram as radiografias da coluna cervical; numà delas, tirada poucos dias após o acidente, via-se fratura da apófise espinhosa da 4 vértebra cervical.

CASo 2 - D.R.S., masculino, prêto, 25 anos, engraxate, foi socorrido no Hospital Getúlio Vargas em 7-12-1961. Fugindo da polícia, mais ou menos às 19,30 horas, o paciente pulou de um muro, com cêrca de $1 \frac{1}{2} \mathrm{~m}$ de altura, caindo ao solo. Este era em rampa e o paciente precipitou-se para diante, indo bater com a fronte num tonel de ferro semienterrado no chāo; a cabeça foi-lhe violentamente projetada para trás; perdeu os sentidos. Deu entrada no hospital às 20,30 horas, desacordado, com pulso cheio, ritmado e lento, respiração irregular, entrecostada de longas pausas. Escoriações na fronte, lábios e cotovelo direito, estando a calça suja de terra na parte anterior, em correspondēncia à bacia e coxas. As 22 horas já recuperara os sentidos, dizendo o nome completo, idade, e referindo-se à maneira como se acidentara. Respiração regular, tipo costal puro, 37 movimentos por minuto. Pulso normal. Tetraplegia. Reflexos tendinosos dos membros superiores e cutâneo-abdominais, ausentes. Reflexos tendinosos dos inferiores, presentes e simétricos, porém diminuídos; reflexos cutâneo-plantares em flexão, diminuidos e simétricos; ausência de reflexos patológicos. As 22,30 horas o paciente começou a recuperar os movimentos do membro inferior esquerdo, os quais, com rapidez tornaram-se aproximadamente normais, com normalização, também, dos reflexos tendinosos. Sensibilidade dolorosa superficial diminuida na metade esquerda do corpo. A falta de cooperação do paciente não permitia exame adequado das outras sensibilidades. Notou-se que o paciente mantinha a cabeça em flexão lateral para a direita, parcial, e rotação parcial do mento para a esquerda.

Na manhã seguinte, o membro inferior direito já executava, fracamente, movimentos de adução e de rotação interna do pé. Membros superiores inteiramente paralisados e sem reflexos. Estes, nos membros pélvicos, eram normais, à exceçāo de um patelar esquerdo muito vivo. Não urinara, até então; começaram-se a observar micçōes automáticas alternadas com periodos de retenção. Radiografias da coluna cervical, de má qualidade, não revelaram fratura. Persistia a posição viciosa da cabeça, como persistiu, atenuada, pelo restante da evolução do caso, a despeito de ter sido posta coleira durante vários dias. Em 10 de dezembro verificou-se estar a sensibilidade tátil, tal como a dolorosa superficial, diminuída na metade esquerda do corpo (os limites da perda sensitiva só puderam ser determinados dias depois). Até êsse dia, terceiro após o acidente, a motilidade do membro inferior direito melhorava lentamente, permanecendo paralíticos os membros torácicos. Começaram a ser notados leves movimentos de ad e abdução do braço esquerdo. Daí por diante, melhora gradativa da motilidade dos membros superior esquerdo e inferior direito, êste já com os reflexos normalizados. Em 11 de dezembro foi verificada diminuição acentuada da sensibilidade vibratória ro membro inferior direito. Em 16-12 voltara o paciente a controlar normalmente as miccōes; melhores condicões de exame permitíram descobrir-se perda da sensibilidade postural segmentar nos membros inferiores.

No $11^{\circ}$ dia após o acidente os reflexos tendinosos dos três membros capazes de movimento, os pélvicos e o torácico esquerdo, eram pràticamente normais. Reflexos cutâneo-plantares ainda diminuidos, porém sempre flexores. Demonstrou-se que a perda da sensibilidade postural segmentar envolvia também os membros superiores. Dêstes, o direito continuava paralisado, porém já com reflexo tricipital nitido e esbôço dos demais. Reflexos cutâneo-abdominais já presentes à esquerda. Em 22 de 
dezembro conseguiu-se evidenciar faixa de hiperestesia entre C2 e C3 à esquerda, com perda da sensibilidade superficial de C3 para baixo; à direita, sensibilidade conservada com, no entanto, sensação associada de formigamento, abaixo do referido nivel. Começou a haver mínima movimentação do membro superior direito no dia 26, isto é, aos 19 dias de acidentado. Em 3 de janeiro de 1962, melhora progressfva da motilidade. Nos membros pélvicos, certo grau de espasticidade, com hiperreflexia e clono de pé, bilaterais. Reflexos cutâneo-plantares sempre flexores. Sinal de Hoffmann bilateral. Sensibilidade, como antes. Alta hospitalar. Tensão arterial em limites normais durante tôda a internação.

Dois meses depois do acidente o exame mostrou: marcha espástica; sinal de Romberg; diminuição da fôrça muscular nos membros direitos; espasticidade nos quatro membros (acentuada no superior direito, moderada no inferior désse lado, leve nos esquerdos); reflexo bicipital "invertido", tanto à direita como à esquerda; demais reflexos osteotendinosos aumentados de intensidade de maneira irregular e, em média, mais à direita do que à esquerda; sinais de Hoffmann, Trömner e Wartenberg bilaterais, mais acentuados à direita; sinais de Rossolimo, Chaddock e Gonda dêsse lado; clono transitório no pé direito; reflexo cutâneo-plantar flexor à direita, dúbio à esquerda; ausência dos reflexos cutâneo-abdominais direitos; diminuição da sensibilidade dolorosa superficial à esquerda, da interlinha C3-C4 para baixo; sensibilidade tátil normal; sensibilidade postural segmentar diminuida no membro pélvico direito, bem como, levemente, a vibratória.

Reexaminado pela última vez em 8-4-63: o paciente melhorara o bastante para voltar à sua profissão de engraxate; marcha espástica, como antes; leve diminuição da fôrça muscular no membro superior direito; espasticidade e hiperreflexia tendinosa nos quatro membros, um tanto mais nos direitos; inversão do reflexo bicipital esquerdo; sinais de Hoffmann e Rossolimo, bilateralmente; clono transitório do pé direito; sinal de Babinski e sinal de Gonda, à direita; persistia a diminuição da sensibilidade dolorosa superficial a esquerda, sem possibilidade de determinar-se o seu limite superior; diminuição da sensibilidade postural segmentar no membro inferior direito.

\section{COMENTARIOS}

Em linhas gerais, o quadro clínico da sindrome traumática central aguda da medula cervical, quando típico e completo, consta de comprometimento motor mais acentuado nos membros superiores que nos inferiores, distúrbios do contrôle do esfíncter vesical e vários graus de perda da sensibilidade. O quadro é causado por traumatismo da coluna cervical; no mais das vêzes por hiperextensão, sem luxação ou fratura da coluna, e em pacientes com espondilartrose. Produzir-se-á mesmo na ausência desta em eventualidades raras ou, não raramente, se houver fratura ou luxação, as quais, inclusive, poderão levar à sindrome por traumatismo de flexão. $O$ quadro clínico regride parcial ou totalmente. O grau de regressão variará, naturalmente, de acôrdo com o tipo de lesão produzido na medula. A lesão, observada nos casos autopsiados, varia desde simples edema do tecido nervoso a amolecimento e, até, hematomielia. A regressão do quadro habitualmente segue marcha característica, excluída a recuperação sensitiva cujo curso é variável. Primeiro volta a motilidade dos membros inferiores, em seguida o contrôle das micções e, finalmente, a motilidade dos membros superiores. A recuperação poder-se-á deter a qualquer ponto, restando seqüelas, inclusive atrofias de músculos da mão.

A fisiopatogenia da síndrome ainda não está bem esclarecida. $\mathrm{Na}$ explicação de como o tecido nervoso se pode lesar numa raque intacta, Schnei- 
der e col, ${ }^{6}$ baseiam-se sobretudo na demonstração feita por Taylor ${ }^{12}$ da possibilidade de, numa hiperextensão forçada do pescoço, o ligamento amarelo preguear-se comprimindo a medula. Apesar daqueles autores discutirem com minúcia os fatôres mecânicos envolvidos no processo de produção da lesão medular, não apresentam uma explicação cabal para a fisiopatogenia da síndrome, nas suas duas primeiras publicações ${ }^{6,7}$. Na segunda ${ }^{7}$ já fazem referência a um possível comprometimento circulatório, ao qual dão maior relêvo nos artigos subseqüentes ${ }^{8,9}$, até exporem, com pormenor, o mecanismo vascular ${ }^{10}$. Tal mecanismo vascular é realçado por Gros e col. ${ }^{1}$ e constitui a fisiopatogenia mais plausível.

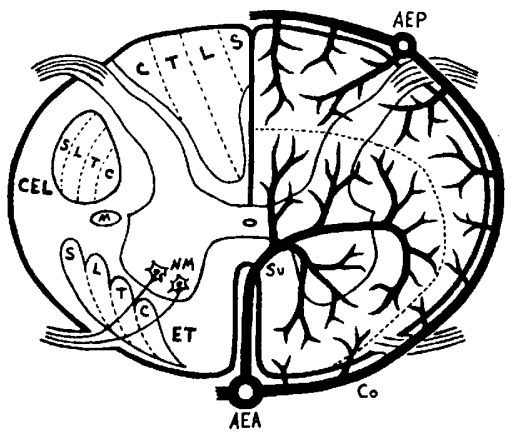

Fig. 1 - Esquema da estrutura anátomofisiológica (à esquerda) e da vascularização arterial (à direita) da medula espinhat.

A figura 1 esquematiza a medula, sua estrutura anátomo-fisiológica e sua vascularização arterial ${ }^{3,9}$. Ao longo do seu trajeto a artéria espinhal anterior (AEA) dá ramos de dois tipos: sulcal ( $\mathrm{Su}$ ) e coronal (Co). Os ramos coronais cursam na superficie, anastomosando-se, de cada lado, com ramos semelhantes da artéria espinhal posterior (AEP). Os ramos das duas artérias espinhais posteriores também se anastomosam entre si. Forma-se, assim, um plexo perimedular que irriga a área periférica, enquanto cada ramo sulcal, penetrando a substância nervosa, distribui-se à zona central de uma metade da medula. Há ramos sulcais para uma e outra metade, emitidos irregularmente ao longo do trajeto da artéria espinhal anterior.

Admitem Schneider e colaboradores que a movimentação crânio-espinhal durante certos traumatismos leva a compressão das artérias vertebrais no interior dos buracos transversos ou na articulação occípito-atloidiana, com diminuição ou parada do fluxo sangüineo na artéria espinhal anterior. Não é, mesmo, impossivel que a insuficiência circulatória assim produzida seja agravada pela compressão direta desta última artéria. Ao distúrbio circulatório poder-se-ão juntar os fatôres mecânicos descritos por aquêles autores ${ }^{6}$. A zona isquemiada da medula corresponde à área de distribuição dos ramos sulcais, abrangida pela linha interrompida na metade direita da figura 1 , sendo a isquemia mais intensa na parte central, diminuindo de intensidade do centro para a periferia da área. A isquemia compromete o feixe corticospinhal lateral (CEL), com mais intensidade as fibras destinadas aos segmentos cervical (C) e torácico (T) que as lombares (L) e sacrais (S), a 
via eferente (M) de contrôle da micção ${ }^{2}$, os neurônios motores (NM) de côrno anterior, e parte do feixe espino-talâmico (ET) e do cordão posterior. Compreendem-se, então, as razōes para o quadro clínico característico da síndrome, quadro impossível de se explicar se contusão ou concussão fôssem os únicos, ou os mais importantes, agentes envolvidos na sua produção. A gravidade das lesões e a possibilidade de reversão das anormalidades clínicas dependerão, sobretudo, da intensidade e duração da isquemia.

A espondilartrose, comumente presente, tem duplo papel. Restringindo o canal raqueano facilita a ação dos fatôres mecânicos sôbre a medula e, talvez, sôbre a artéria espinhal anterior. Por outro lado, facilita a compressão das artérias vertebrais ${ }^{9,11}$.

Dos dois casos aqui apresentados, no primeiro não se pôde determinar exatamente a maneira como foi sofrido o traumatismo e se houve hiperextensão do pescoço. Estava presente, como é regra, espondilartrose. A sintomatologia instalou-se alguns momentos após o acidente, fato incomum porém não inédito. Tendo sido o paciente visto sỏmente alguns meses após o acidente, o diagnóstico baseou-se na história e nas seqüelas, do tipo das que soem ocorrer na sindrome.

O segundo caso resultou de traumatismo em condiçōes típicas, com hiperextensão forçada do pescoço, causando perturbação medular extensa, nāo só no sentido transversal como no rostro-caudal. O comprometimento da motilidade diafragmática, as alteraçōes sensitivas e a "inversão" dos reflexos bicipitais, sugerem lesão de C2 a C5. Por outro lado, às manifestações habituais à sindrome associaram-se sinais de uma sindrome de Brown-Séquard atipica. Possivelmente ao distúrbio circulatório juntou-se contusão da medula por luxação da coluna, luxação que deve ter realmente ocorrido apesar de não se a ter podido documentar radiològicamente.

O valor prático do conhecimento da síndrome aqui comentada reside em dois fatos. Primeiro, ser contra-indicada a intervenção cirúrgica, por ineficaz ou, mesmo, nociva. Depois, por cermitir a formulação de um prognóstico relativamente bom, ao tratamento conservador, pois há sempre regressão do quadro, não raro completa.

\section{RESUMO}

São relatados dois casos de sindrome traumática central aguda da medula cervical, sendo comentados os aspectos clínicos e fisiopatogênicos e ressaltado o valor prático do seu conhecimento.

\section{SUMMARY}

Syndrome of acute central cervical spinal cord injury.

Two cases of the syndrome of acute central cervical spinal cord injury are repcrted; its clinical and physiopathogenic features are commented and the practical value of its knowledge is emphasized. 


\section{REFERENCIAS}

1. GROS, C.; VLAHOVITCH, B. \& MOHASSEB, G. - Une forme peu connue de tetraplégie traumatique. Presse méd., 118:829-830 (abril, 30) 1960. 2. NATHAN, P. W. \& SMITH, M. C. - The centrifugal pathway for micturition within the spinal cord. J. Neurol. Neurosurg. Psychiat., 21:177-185, 1958. 3. PEELE, T. L. - The Neuroanatomical Basis for Clinical Neurology. McGraw Hill Book Co., New York, 1954. 4. RAND, W. R. \& CRANDALL, P. H. - Central spinal cord syndrome in hyperextension injuries of the cervical spine. J. Bone Jt. Surg., 44(A):1415-1422, 1962. 5. SCHNEIDER, R. C. - Chronic neurological sequelae of acute trauma to the spine and spinal cord: the syndrome of acute central cervical spinal cord injury followed by chronic anterior cervical cord injury. J. Bone Jt. Surg., 42(A):253-260, 1960. 6. SCHNEIDER, R. C.; CHERRY, G. \& PANTEK, H. - The syndrome of acute central cervical spinal cord injury. With special reference to the mechanisms involved in hyperextension injuries of the cervical cord. J. Neurosurg., 11:546577, 1954. 7. SCHNEIDER, R. C.; THOMPSON, J. M. \& BEBIN, J. - The syndrome of acute central cervical spinal cord injury. J. Neurol. Neurosurg. Psychiat., 21: 216-227, 1958. 8. SCHNEIDER, R. C. \& CROSBY, E. C. - Váscular insufficiency of brain stem and spinal cord in spinal trauma. Neurology 9:643-656, 1959. 9. SCHNEIDER, R. C.; REIFEL, E.; CRISLER, H. O. \& OOSTERBAAN, B. G. - Football injuries of the head and spinal cord. J. Amer. med. Ass., 177:362-367 (agôsto, 12) 1961. 10. SCHNEIDER, R. C. \& SCHEMM, G. W. - Vertebral artery insufficiency in acute and chronic spinal trauma. With special reference to the syndrome of acute central cervical spinal cord injury. J. Neurosurg., 18:348-360, 1961. 11. TATLOW, W. F. T. \& BAMMER, H. G. - Syndrome of vertebral artery compression. Neurology $7: 331-340,1957$. 12. TAYLOR, A. R. - The mechanism of injury to the spinal cord in the neck without damage to the vertebral column. J. Bone Jt. Surg., 33(B):543-547, 1951.

Hospital Prof. Edgard Santos - Salvador, Bahia - Brasil. 